\title{
Butterflies in urban parks in the Bangkok Metropolitan Region, Thailand
}

\author{
Narong Jaturas ${ }^{\ddagger}$, Kong-Wah Sing§,, John-James Wilsonף,, , Hui Dong ${ }^{\#}$ \\ ‡ Department of Microbiology and Parasitology, Faculty of Medical Science, Naresuan University, Phitsanulok, Thailand \\ $\S$ Arthropod Ecology and Biological Control Research Group, Ton Duc Thang University, Ho Chi Minh City, Vietnam \\ | Faculty of Applied Sciences, Ton Duc Thang University, Ho Chi Minh City, Vietnam \\ II Vertebrate Zoology at World Museum, National Museums Liverpool, Liverpool, United Kingdom \\ \# Fairy Lake Botanical Garden, Shenzhen \& Chinese Academy of Sciences, Shenzhen, China
}

\begin{abstract}
Corresponding author: Narong Jaturas (narongja@nu.ac.th), Kong-Wah Sing (singkongwah@tdtu.edu.vn), Hui Dong (donghui@szbg.ac.cn)

Academic editor: Martin Wiemers

Received: 08 Jul 2020 | Accepted: 01 Sep 2020 | Published: 12 Oct 2020

Citation: Jaturas N, Sing K-W, Wilson J-J, Dong H (2020) Butterflies in urban parks in the Bangkok Metropolitan Region, Thailand. Biodiversity Data Journal 8: e56317. https://doi.org/10.3897/BDJ.8.e56317
\end{abstract}

\section{Abstract \\ Background}

For residents of East-Southeast Asia's megacities, interactions with "nature" may be largely limited to interactions taking place in urban parks. Urban parks provide refuges for ecologically-important biodiversity, such as insect pollinators. While residents may be unlikely to notice small insects, butterflies are more likely to be noticed and to provide positive human-"nature" interactions. Engaging residents and city planners in promoting habitat for butterflies is valid conservation practice and has well-understood educational and well-being benefits. Surveying and monitoring is an essential activity to corroborate, improve and communicate the outcomes of conservation practices amongst city governments, scientists and other stakeholders. Here we present the data from a survey of butterflies in urban parks in the megacity of the Bangkok Metropolitan Region as part of the "Urban biodiversity and human well-being in East-Southeast Asia's megacities" project organised by the "Urban Butterflies in Asia Research Network". 


\section{New information}

We recorded 51 species of butterflies from ten urban parks in the Bangkok Metropolitan Region. This was more than double the 25 species reported in Bangkok's City Biodiversity Index application. However, this was lower than that recorded in other megacities in Southeast Asia, such as Kuala Lumpur at 60 species. Most of the butterflies recorded were common and widespread species. DNA barcodes are provided for most of the butterflies sampled.

\section{Keywords}

Bangkok, butterflies, DNA barcodes, parks, Southeast Asia, Thailand, urban

\section{Introduction}

East-Southeast Asia has seen the fastest rates of urbanisation globally (Schneider et al. 2015). A consequence of urbanisation is that residents have less exposure to "nature". The loss of an emotional connection with nature is closely associated with not only the decline in people's willingness to protect nature (Imai et al. 2018), but also reduced psychological well-being (Soga and Gaston 2016). Urban planning often incorporates public parks, providing improved air quality and opportunities for recreation. For residents of EastSoutheast Asia's megacities, interactions with "nature" may be largely limited to interactions taking place in urban parks. While residents may be unlikely to notice small insects such as bees, butterflies are more likely to be noticed and to provide positive human-"nature" interactions (Wilson et al. 2015). Engaging residents and city planners in promoting habitat for butterflies is valid conservation practice and has well-understood educational and well-being benefits (Hall et al. 2017). Surveying and monitoring is an essential activity to corroborate, improve and communicate the outcomes of conservation practices amongst city governments, scientists and other stakeholders (Hall et al. 2017, Ramírez-Restrepo and MacGregor-Fors 2016). This is clearly demonstrated by change in number of butterfly species being a mandatory indicator in the City Biodiversity Index (or Singapore Index) (Secretariat Convention on Biological Diversity 2013, Uchiyama and Kohsaka 2019). Here we present the data from a survey of butterflies in urban parks in the megacity of the Bangkok Metropolitan Region as part of the "Urban biodiversity and human well-being in East-Southeast Asia's megacities" project organised by the "Urban Butterflies in Asia Research Network" (Sing et al. 2017, Wilson and Sing 2020). Twenty-five species of butterflies have previously been reported within the city limits of Bangkok according to the City Biodiversity Index application (dated October 2012), but in view of the species richness of the region, this seems an underestimate. We recorded 51 species of butterflies from ten urban parks in the Bangkok Metropolitan Region. 


\section{Project description}

Title: Urban biodiversity and human well-being in East-Southeast Asia's megacities

Personnel: The "Urban Butterflies in Asia Research Network" involves researchers across East-Southeast Asia. Information can be found on the project's website (Wilson and Sing 2020) and ResearchGate project page ( https://www.researchgate.net/project/UrbanButterflies-in-Asia-Research-Network).

Study area description: In urban green spaces, such as city parks, native insects provide important ecosystem services including pollination of plants that provide food for humans and other animals and enrich human well-being. These important services proceed largely unnoticed and have received limited attention. Several studies of insect diversity in city parks, thought of as urban wildlife refuges, have been conducted in Europe and North America, but few have been conducted in rapidly urbanising countries in East-Southeast Asia (Ramírez-Restrepo and MacGregor-Fors 2016). Without further research into the diversity of insects in urbanisation hotspots, we cannot predict how future development will affect the ecosystem services and benefits they provide. Our project focuses on megacities across the region (Fig. 1) and on butterflies - a model "biodiversity indicator" group for biodiversity studies (Syaripuddin et al. 2015).

Design description: We will (1) generate data from urban parks in megacities across EastSoutheast Asia to enable region-wide meta-analyses of butterfly diversity in this rapidly urbanising region (Sing et al. 2017); (2) examine the value of urban parks as refuges for butterflies through investigating the relationships between butterfly species richness and the age, size and distance from the central business district of parks in East-Southeast Asian cities (Sing et al. 2016a, Sing et al. 2016b, Sing et al. 2019); (3) identify which type of microhabitat within urban parks provides suitable breeding and foraging habitat for butterflies (Sing et al. 2016a, Sing et al. 2016b); and (4) contribute to DNA barcode reference libraries of urban butterflies to enable rapid surveys of these species in future studies (Wilson et al. 2013).

Funding: The project has received funding from the Asia-Pacific Network for Global Change Research (CRYS2017-03SY-Sing); Fundamental Research Funds for the Central Nonprofit Research Institution of CAF (CAFYBB2020ZB008); Biodiversity Conservation Programme of the Ministry of Ecology and Environment, China (China-BON Butterflies) (SDZXWJZ01059-2018). We have also received support from the Kunming Institute of Zoology, Chinese Academy of Sciences; Fairy Lake Botanical Garden, Shenzhen \& Chinese Academy of Sciences; Naresuan University, Thailand. We are grateful to all the park managers and local authorities who have provided permission to conduct butterfly surveys and supported the project (in kind) in many ways. 


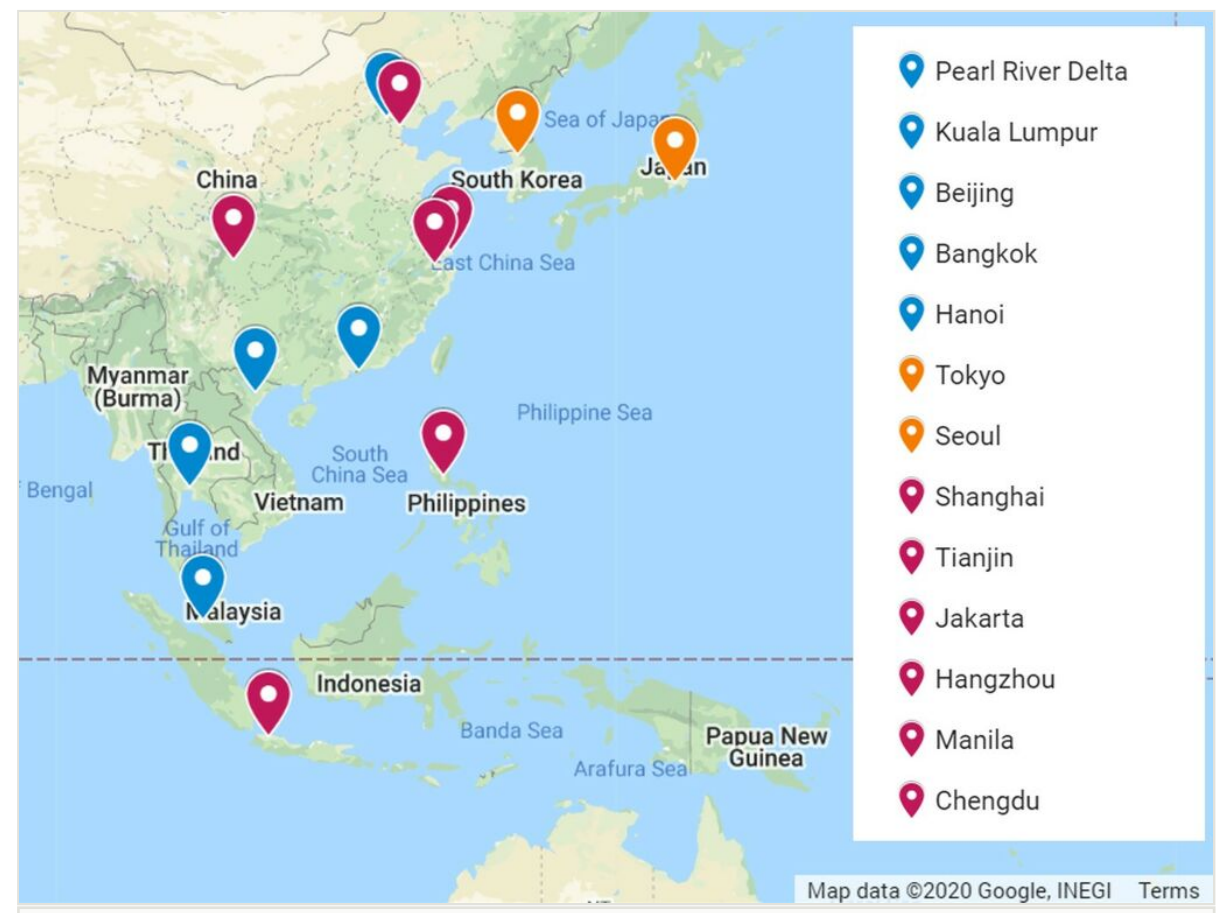

Figure 1. doi

Megacities in East-Southeast Asia featured in Figure 1 of Schneider et al. (2015). Butterfly sampling has been completed in urban parks by the "Urban Butterflies in Asia Research Network" (Sing et al. 2017, Sing et al. 2016a, Sing et al. 2016b, Sing et al. 2019, Wilson and Sing 2020) at those megacities with blue markers. Butterfly sampling has been completed in urban parks by other researchers (Matsumoto 2015, Nagase et al. 2019, Lee et al. 2015) at those megacities with orange markers. To our knowledge, no butterfly sampling has been published for urban parks at those megacities with magenta markers.

\section{Sampling methods}

Study extent: Ten parks managed by the Bangkok Metropolitan Authority were selected for sampling (Fig. 2). These represent a range of park areas, ages and degree of urbanisation i.e. distance from the urban core.

Sampling description: Each park was sampled over three consecutive days comprising 180 minutes each day. We followed an active search-timed survey method used in our butterfly surveys in Kuala Lumpur (Sing et al. 2016b), Shenzhen (Sing et al. 2016a) and Beijing (Sing et al. 2019), where butterflies were collected during the 180 minutes survey period within accessible areas. This method allowed a full search of green areas in parks and avoided sampling biases due to differences in size and shape between parks. Butterflies were collected by an experienced collector using a hand net between 09:00 $\mathrm{h}$ and $14: 00 \mathrm{~h}$ during calm weather to correspond with the peak flight activity period of most adult butterflies. 


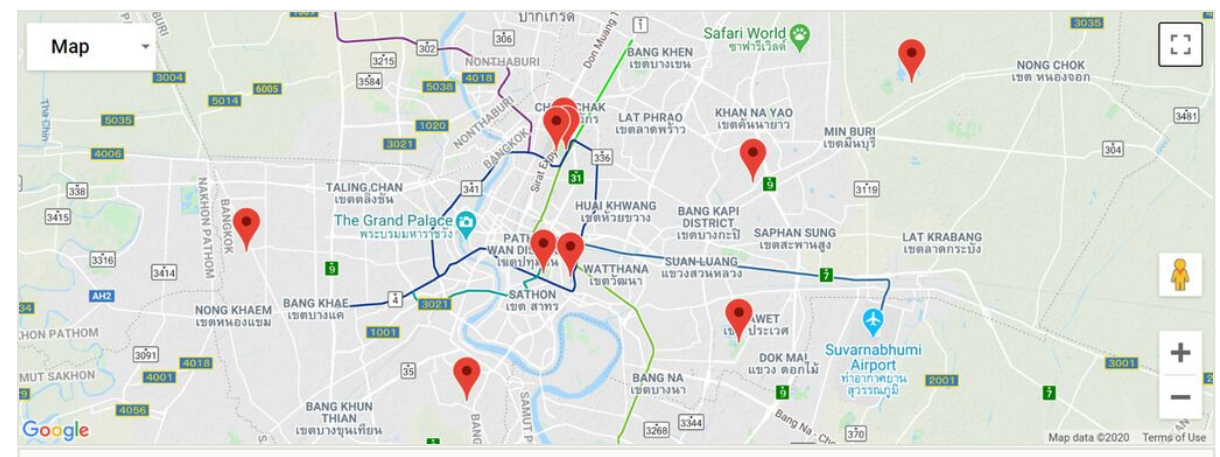

Figure 2. doi

Location of ten parks within the Bangkok Metropolitan Region where we conducted butterfly surveys.

\section{Quality control: Sampling limitations}

While we followed a standardised sampling approach to aid comparison with surveys conducted in other megacities, the number of species recorded will have been limited by the collecting method (i.e. hand net only, no bait trapping), time of day (i.e. crepusular species could be missed) and the season (i.e. some species will not have been present as adults at this time of year).

\section{Species identification}

We combined both morphological methods (i.e. comparision with images and descriptions in Ek-Amnuay 2012) and DNA barcoding (i.e. matches in the DNA barcode library) for species identification. All collected butterflies were brought back to the university. DNA was extracted from a single leg, or 2-3 legs in the case of small lycaenids, of each butterfly using the TIANamp extraction kit following the manufacturer's instructions (Tiangen Biotech, Beijing). DNA barcode fragments of COI mtDNA were amplified (following standard protocols in Wilson 2012) using LCO1490/HCO2198 primers. PCR products were Sanger-sequenced and checked for quality (following standard protocols in Wilson et al. 2019). Specimen data and any generated DNA barcodes were submitted to Barcode of Life Datasystems (BOLD; Ratnasingham and Hebert 2007). In BOLD, the DNA barcodes were automatically sorted into Barcode Index Numbers (BINs; Ratnasingham and Hebert 2013) which greatly aided the application of names to specimens with sequences. At present, five species could only be given a genus name (from genera, Borbo, Parnara and Pelopidas) (Suppl. material 1); however, these may be updated as the BOLD library grows and the taxonomy applied in BOLD is refined.

\section{Geographic coverage}

Description: Bangkok Metropolitan Region, Thailand

Coordinates: 13.495 and 13.955 Latitude; 100.328 and 100.938 Longitude. 


\section{Taxonomic coverage}

Taxa included:

\begin{tabular}{|l|l|l|}
\hline Rank & Scientific Name & Common Name \\
\hline superfamily & Papilionoidea & True butterflies \\
\hline superfamily & Hesperioidea & Skipper butterflies \\
\hline
\end{tabular}

\section{Temporal coverage}

Data range: 2017-7-30 - 2017-8-18.

\section{Usage rights}

Use license: Creative Commons Public Domain Waiver (CC-Zero)

\section{Data resources}

Data package title: Bangkok Urban Butterflies

Resource link: http://www.boldsystems.org/index.php/Public SearchTerms?query=DSBKKUB

\section{Number of data sets: 2}

Data set name: DS-BKKUB (Bangkok Urban Butterflies)

\section{Download URL: $\underline{\text { dx.doi.org/10.5883/DS-BKKUB }}$}

Data format: DWC; XML; TSV

Description: The dataset contain 693 records and 438 COI DNA barcodes grouped into 43 BINS. Below are listed the columns for the DWC format.

\begin{tabular}{|l|l|}
\hline Column label & Column description \\
\hline id & BOLD Process ID \\
\hline occurrencelD & BOLD Process ID \\
\hline catalogNumber & BOLD Specimen ID \\
\hline fieldNumber & BOLD Specimen ID/Field number \\
\hline identificationRemarks & BIN number \\
\hline basisOfRecord & $\begin{array}{l}\text { Because these records are held on the Barcode of Life Datasystems this is recorded as } \\
\text { "DNA Barcode" }\end{array}$ \\
\hline
\end{tabular}




\begin{tabular}{|c|c|}
\hline institutionCode & Code for the institution currently holding the physical specimen \\
\hline phylum & Taxonomic phylum \\
\hline class & Taxonomic class \\
\hline order & Taxonomic order \\
\hline family & Taxonomic family \\
\hline genus & Taxonomic genus \\
\hline scientificName & Taxonomic species name \\
\hline identifiedBy & Taxonomic determiner \\
\hline habitat & Collection habitat \\
\hline eventDate & Collection date \\
\hline recordedBy & Collector \\
\hline country & Collection country \\
\hline stateProvince & Collection state/province \\
\hline locality & Precise collection locality/urban park \\
\hline decimalLatitude & Decimal latitude \\
\hline decimalLongitude & Decimal longitude \\
\hline lifestage & Lifestage of the specimen when collected \\
\hline rightsHolder & Holder of the rights \\
\hline rights & Creative commons licence applied \\
\hline language & Language used for the record \\
\hline
\end{tabular}

Data set name: Bangkok Urban Parks Butterfly Species Checklist

Download URL: see Supplementary files

Data format: Excel 97-2003 Workbook ( $\left.{ }^{*} . x \mid s\right)$

Description: A checklist of species found in each urban park (Suppl. material 1).

\begin{tabular}{|l|l|}
\hline Column label & Column description \\
\hline Butterfly family & Butterfly family \\
\hline Butterfly species & Butterfly species \\
\hline $\begin{array}{l}\text { Barcode Index Number (BIN) for } \\
\text { the species }\end{array}$ & $\begin{array}{l}\text { Barcode Index Number (BIN) for the species [Inferred BIN in the case where } \\
\text { specimens were not sequenced is given in parentheses] }\end{array}$ \\
\hline Benchakitti Park & Species recorded in Benchakitti Park (indicated by a "Y") \\
\hline
\end{tabular}




\begin{tabular}{|l|l|}
\hline Chatuchak Park & Species recorded in Chatuchak Park (indicated by a "Y") \\
\hline Lumphini Park & Species recorded in Lumphini Park (indicated by a "Y") \\
\hline Queen Sirikit Park & Species recorded in Queen Sirikit Park (indicated by a "Y") \\
\hline Rama IX Park & Species recorded in Rama IX Park (indicated by a "Y") \\
\hline Seri Thai Park & Species recorded in Seri Thai Park (indicated by a "Y") \\
\hline Thonburirom Park & Species recorded in Thomburirom Park (indicated by a "Y") \\
\hline Thawee Wanarom Park & Species recorded in Thawee Wanarom Park (indicated by a "Y") \\
\hline Wachirabenchatat Park & Species recorded in Wachirabenchatat Park (indicated by a "Y") \\
\hline Wareepirom Park & Species recorded in Wareepirom Park (indicated by a "Y") \\
\hline
\end{tabular}

\section{Acknowledgements}

We are grateful to Naresuan University for supporting this project, the Department of Environment of the Bangkok City and the Office of the Public Parks, Bangkok City, Bangkok, Thailand for permission to conduct a butterfly survey in Bangkok (permission letter number BKK 1106/4557, dated 20 July 2017). We also thank the directors and staff of the ten urban parks for their help and cooperation during our surveys. Anonymous reviewers aided considerably in the morphological indentifications.

\section{Author contributions}

NJ, KWS, JJW and HD contributed to the study design and materials and reagents. NJ, KWS and JJW conducted sampling and identifications. KWS and JJW performed the sequence analyses and drafted the paper. All authors have read and approved the final manuscript.

\section{References}

- $\quad$ Ek-Amnuay P (2012) Butterflies of Thailand. 2nd Edition. Baan Lae Suan Amarin Printing, Bangkok. [ISBN 6162079880]

- Hall D, Camilo G, Tonietto R, Ollerton J, Ahrné K, Arduser M, Ascher J, Baldock KR, Fowler R, Frankie G, Goulson D, Gunnarsson B, Hanley M, Jackson J, Langellotto G, Lowenstein D, Minor E, Philpott S, Potts S, Sirohi M, Spevak E, Stone G, Threlfall C (2017) The city as a refuge for insect pollinators. Conservation Biology 31 (1): 24-29. https://doi.org/10.1111/cobi.12840

- Imai H, Nakashizuka T, Kohsaka R (2018) An analysis of 15 years of trends in children's connection with nature and its relationship with residential environment. Ecosystem Health and Sustainability 4 (8): 177-187. 
- $\quad$ Lee CM, Park JW, Kwon T, Kim S, Ryu JW, Jung SJ, Lee SK (2015) Diversity and density of butterfly communities in urban green areas: an analytical approach using GIS. Zoological Studies 54 (1). https://doi.org/10.1186/s40555-014-0090-7

- Matsumoto K (2015) Habitat specificity of butterflies along urban environmental gradients in Tama City, Tokyo. Entomological Science 18 (4): 509-518. https://doi.org/10.1111/ens.12146

- $\quad$ Nagase A, Kurashina M, Nomura M, Maclvor JS (2019) Patterns in urban butterflies and spontaneous plants across a University campus in Japan. The Pan-Pacific Entomologist 94 (4). https://doi.org/10.3956/2018-94.4.195

- Ramírez-Restrepo L, MacGregor-Fors I (2016) Butterflies in the city: a review of urban diurnal Lepidoptera . Urban Ecosystems 20 (1): 171-182. https://doi.org/10.1007/ s11252-016-0579-4

- $\quad$ Ratnasingham S, Hebert PDN (2007) BARCODING: bold: The Barcode of Life Data System (http://www.barcodinglife.org). Molecular Ecology Notes 7 (3): 355-364. https://doi.org/10.1111/j.1471-8286.2007.01678.x

- Ratnasingham S, Hebert PN (2013) A DNA-based registry for all animal species: The Barcode Index Number (BIN) System. PLoS ONE 8 (7). https://doi.org/10.1371/ journal.pone.0066213

- Schneider A, Mertes CM, Tatem AJ, Tan B, Sulla-Menashe D, Graves SJ, Patel NN, Horton JA, Gaughan AE, Rollo JT, Schelly IH, Stevens FR, Dastur A (2015) A new urban landscape in East-Southeast Asia, 2000-2010. Environmental Research Letters 10 (3). https://doi.org/10.1088/1748-9326/10/3/034002

- Secretariat Convention on Biological Diversity (2013) City Biodiversity Index (or Singapore Index). https://www.cbd.int/subnational/partners-and-initiatives/citybiodiversity-index. Accessed on: 2020-7-01.

- $\quad$ Sing K, Dong H, Wang W, Wilson J (2016a) Can butterflies cope with city life? Butterfly diversity in a young megacity in southern China. Genome 59 (9): 751-761.

https://doi.org/10.1139/gen-2015-0192

- $\quad$ Sing K, Jusoh WA, Hashim NR, Wilson J (2016b) Urban parks: refuges for tropical butterflies in Southeast Asia? Urban Ecosystems 19 (3): 1131-1147.

https://doi.org/10.1007/s11252-016-0542-4

- $\quad$ Sing K, Wang W, Wilson J (2017) Butterfly diversity in Asia's megacities. Genome 60 (11): 997.

- $\quad$ Sing K, Luo J, Wang W, Jaturas N, Soga M, Yang X, Dong H, Wilson J (2019) Ring roads and urban biodiversity: distribution of butterflies in urban parks in Beijing city and correlations with other indicator species. Scientific Reports 9 (1): 7653.

https://doi.org/10.1038/s41598-019-43997-8

- Soga M, Gaston KJ (2016) Extinction of experience: the loss of human-nature interactions. Frontiers in Ecology and the Environment 14 (2): 94-101.

https://doi.org/10.1002/fee.1225

- $\quad$ Syaripuddin K, Sing K, Wilson J (2015) Comparison of butterflies, bats and beetles as bioindicators based on four key criteria and DNA Barcodes. Tropical Conservation Science 8 (1): 138-149. https://doi.org/10.1177/194008291500800112

- Uchiyama Y, Kohsaka R (2019) Application of the City Biodiversity Index to populated cities in Japan: Influence of the social and ecological characteristics on indicator-based management. Ecological Indicators 106 https://doi.org/10.1016/j.ecolind.2019.05.051 
- Wilson J, Sing K, Sofian-Azirun M (2013) Building a DNA barcode reference library for the true butterflies (Lepidoptera) of Peninsula Malaysia: What about the subspecies? PLOS One 8 (11): e79969. https://doi.org/10.1371/journal.pone.0079969

- Wilson J, Jisming-See S, Brandon-Mong G, Lim A, Lim V, Lee P, Sing K (2015) Citizen Science: The first Peninsular Malaysia Butterfly Count. Biodiversity Data Journal 3: e7159. https://doi.org/10.3897/BDJ.3.e7159

- Wilson J, Sing K, Jaturas N (2019) DNA Barcoding: Bioinformatics workflows for beginners. Encyclopedia of Bioinformatics and Computational Biology 985-995. https://doi.org/10.1016/b978-0-12-809633-8.20468-8

- Wilson J, Sing K (2020) Urban butterflies in Asia research network. http://uba-net.simplesite.com/. Accessed on: 2020-7-01.

- Wilson JJ (2012) DNA Barcodes for Insects. DNA Barcodes 17-46. https://doi.org/10.1007/978-1-61779-591-6 3

\section{Supplementary material}

\section{Suppl. material 1: Bangkok Urban Parks Butterfly Species Checklist doi}

Authors: Narong Jaturas, Kong-Wah Sing, John-James Wilson, Hui Dong

Data type: Species occurences

Download file $(47.00 \mathrm{~kb})$ 